\title{
Evaluation of the vibration performance response of insulating floor panels under human walking conditions
}

\author{
Evaluación del desempeño vibratorio de paneles de piso aislantes sometidos a desplazamientos \\ de personas
}

Alexander Opazo Vega (Main and Contact Author)

Universidad del Bío-Bío, Facultad de Ingeniería, Departamento de Ingeniería Civil y Ambiental.

Avenida Collao 1202, Concepción, Chile, CP 4051381. +56 413111645

aopazove@ubiobio.cl

Peter Dechent Anglada.

Universidad de Concepción, Facultad de Ingeniería, Departamento de Ingeniería Civil

pdechen@udec.cl

Patricio Cendoya Hernandez.

Universidad de Concepción, Facultad de Ingeniería, Departamento de Ingeniería Civil

pcendoya@udec.cl

Cristian Molina Vicuña

Universidad de Concepción, Facultad de Ingeniería, Departamento de Ingeniería Mecánica

crimolin@udec.cl

Manuscript Code: 238

Date of Acceptance/Reception: 01.08.2016/06.08.2014

\begin{abstract}
:
The use of lightweight prefabricated floor panels has grown considerably over the last two decades. Previous studies have shown a detrimental vibrational response of these floors under human walking conditions, resulting in user complaints. The present study evaluates the vibration performance of a newly developed construction system in Chile, composed of deck-type insulating floor panels installed in dwellings constructed with ferro-cement prefabricated construction panels. The vibrations induced by walking steps were measured in $36 \mathrm{dwellings}$ of three different models. Individual synchronized walks were performed at different step frequencies with individuals of different weights. For the evaluation, the serviceability criteria and vibration performance indicators proposed in the ISO 10137 standard were used. The results show that the floor panels have an impulsive vibration response with average vertical natural frequencies of $26.14 \mathrm{~Hz}$ and damping ratios of $4.3 \%$. In the dwellings with a lower damping ratio, the performance indicators presented unfavorable values when the heaviest individuals walked at the greatest step frequency. If the serviceability criteria are implemented, it is predicted that $97.22 \%$ of the floor panels will not generate significant user discomfort, validating the construction system.
\end{abstract}

Keywords: vibrations in floors, vibration performance, dynamic serviceability, lightweight floors, human-induced vibrations.

Resumen:

El uso de entrepisos livianos y prefabricados ha crecido considerablemente en las dos últimas décadas. Estudios previos demuestran que estos pisos pueden presentar problemas vibratorios debido al caminar de las personas, generando reclamos de los usuarios. En este trabajo se evalúa el desempeño vibratorio de un sistema constructivo inédito en Chile, conformado por paneles de entrepiso aislantes tipo deck, que se instalan en viviendas construidas con muros prefabricados de ferrocemento. Se miden las vibraciones inducidas por caminatas en 36 viviendas, de 3 modelos distintos. En cada vivienda se realizan caminatas sincronizadas individuales a distintas frecuencias de paso, con sujetos de distinto peso. Para la evaluación se utilizan los criterios de serviciabilidad e indicadores de desempeño vibratorio propuestos en la norma ISO 10137. Los resultados muestran que los entrepisos tienen una respuesta vibratoria impulsiva, con frecuencias naturales verticales promedio de $26,14 \mathrm{~Hz}$ y razones de amortiguamiento de 4,3\%. En las viviendas con menor razón de amortiguamiento, los indicadores de desempeño presentan valores desfavorables, cuando los individuos de mayor peso caminan a la mayor frecuencia de paso. La aplicación de los criterios de serviciabilidad prevé que el 97,22\% de los entrepisos no generarán molestias significativas en los usuarios, validando al sistema constructivo.

Palabras claves: vibraciones en pisos, desempeño vibratorio, serviciabilidad dinámica, pisos livianos, vibraciones inducidas por personas.

Introduction

In the construction industry, the use of lightweight, easily mounted prefabricated floor systems has grown considerably over the last two decades. The need to minimize construction times, along with the technological advances associated with this industry, have prompted the emergence of a series of industrialized, prefabricated modular construction solutions (Bernstein, Gudgel, \& Laquidara-Carr, 2011). These systems must guarantee adequate performance in the areas of security and structural serviceability, fire resistance, energy efficiency and acoustic insulation, which can be difficult to evaluate. 
The present study evaluates the vibration performance induced by humans walking on state-of-the-art lightweight deck-type insulating floor systems developed by NOVA Chemicals ${ }^{\circledR}$ and SYNTHEON ${ }^{\circledR}$. These panels were installed in single-family dwellings constructed with ferro-cement prefabricated walls, generating a completely new combination of materials in Chile that favors rapid construction and energy efficiency. However, the vibration performance of these panels in the previously mentioned construction context is unknown, thus justifying their study.

To achieve the goals outlined in this study, an experimental design was executed, in which human walking-induced vibrations were measured in 36 dwellings of three different models with installed insulating floor panels. In each dwelling, individual synchronized walks were performed at different step frequencies, with individuals of different weights. The serviceability criteria and vibration performance indicators proposed in the ISO 10137 standard were used because of their acceptance worldwide (Setareh, 2012) .

Problem description

Floor systems are the only structural components of a building that are in continuous physical contact with the users, whether it is in the context of residential, commercial or industrial use (Hu, Chui, \& Onysko, 2001). Previous studies have shown that when these floors are lightweight and are used in projects with free architectural plans, they can be susceptible to excessive vertical vibration problems that are basically induced by humans walking on the floors (Hanagan, Raebel, \& Trethewey, 2003). When the level of the generated vibrations exceeds the perception threshold of humans, it is highly likely that claims and adverse comments will be made by the users. This issue, which is becoming more recurrent in diverse construction contexts, has generated a sustained increase in research associated with the dynamic serviceability of floor systems (Middleton \& Brownjohn, 2010) and other structural elements (Morán Proaño \& Álvarez Rodríguez, 2012). Therefore, it is necessary to evaluate the dynamic serviceability on-site each time that a newly developed floor system is built. In this way, its vibration performance can be predicted in a series of respective walk scenarios, thus avoiding eventual future claims by the users.

\section{State of the Art}

One of the first studies on the human response to dynamic loads in floor systems was performed by Reiher and Meister (1931). These researchers introduced a categorization scale of human vibration perceptions that ranges from "imperceptible" to "very annoying". Lenzen (1966) proposed the Reiher-Meister modified scale for vibrations induced by the impacts of walks, modeling the vibrations in floors as transient phenomena. A decade later, Wiss and Parmelee (1974) proposed an acceptability scale based on the initial amplitude, frequency and damping ratio of the vibration induced by walks. Allen and Rainer (1976) developed criteria to avoid annoying vibrations in floor systems composed of concrete slabs and metallic beams of large spans in the context of residential and office buildings.

In the 1980s, on-site evaluations of the vibration performance of lightweight floors due to humans walking on them started to be performed. Onysko (1988) conducted a field study in wood floors of dwellings that were designed according to the traditional deflection control criteria. In most cases, the users were not satisfied with the vibration performances of their floors, and thus, the need for generating new design criteria considering serviceability was detected. Accordingly, the International Organization for Standardization (ISO) published standards in the context of vibration serviceability, especially versions ISO 2631-1 (International Organization for Standardization, 1997), ISO 2631-2 (International Organization for Standardization, 2003) and ISO 10137 (International Organization for Standardization, 2007). These standards include requirements for the evaluation of the human exposure to vibrations and contain the basis for the serviceable design of buildings and pedestrian walkways subjected to vibrations; these standards are being adopted by diverse countries (Setareh, 2010).

In the last six years, the field studies conducted by Parnell, Davis \& Xu (2010) and Xiong, Kang \& Lu (2011) stand out. In the first study, the vibration performance of different construction typologies of lightweight floors with cold-formed metallic beams was evaluated. The floor systems were outfitted with accelerometers, and impact tests and walks were performed on 43 laboratory prototypes and dwellings. The vibration performance of the floor systems was evaluated according to the serviceability criteria proposed by the ISO 2631-2 standard (International Organization for Standardization, 1989). The second study evaluated the vibration performance of 13 wood floors in Chinese educational institutions. The environmental vibrations, impact tests and walks of both individuals and groups were measured. All of the instrumented floor systems were evaluated according to the dynamic serviceability criteria required by the current Chinese standards. 
As a result of the contribution of research studies conducted in these fields, diverse design guides have emerged for the control of vibrations in floor structures (Murray, Allen \& Ungar, 2003; Willford \& Young, 2006; Feldmann, Heinemeyer \& Völling, 2007; Smith, Hicks, \& Devine, 2007). However, these publications focused on traditional floor systems of concrete and steel and did not recommend their direct application in floor systems built with unconventional lightweight materials (Abeysinghe, Thambiratnam \& Perera, 2013).

\section{Methodology}

\section{Construction characterization of the floor systems evaluated.}

The Deck-type Insulating Floor Panels (DIFP) are formwork systems for reinforced concrete floors made from expanded polystyrene plastic foams of high density $(20 \mathrm{~kg} / \mathrm{m3})$. These panels have a modular configuration with thicknesses between 15 and $29 \mathrm{~cm}$ and are $60 \mathrm{~cm}$ wide in the lower part. In the inner part, each module contains two galvanized steel channels " $C$ ", separated by a distance of $30 \mathrm{~cm}$, with holes for the passage of the installations. The particular shape of the modules and the configuration that they generate when they are laterally interconnected provide the space to form claddings and joists of reinforced concrete that increase the resistance of the system. For the purposes of this investigation, the deck-type insulating floor panel system and its respective reinforced concrete claddings and joists are abbreviated as DIFP-RC. Figure 1 shows construction details of the aforementioned floor system.

In this study, 36 dwellings of three different models were evaluated that were in the construction termination phase but did not have their floor coverings installed. The slabs were instrumented with two accelerometers that were placed in the zones of maximum vibration amplitude. The signals were recorded with a sampling frequency of 1000 $\mathrm{Hz}$. Table 1 shows the geometric characteristics of the most unfavorable slabs evaluated in each dwelling model.

Figure 1. Construction process of the DIFP-RC system: a) Individual prefabricated modules, b) Preliminary installation on walls, c) Transverse view of the system. Source: Self-Elaboration.

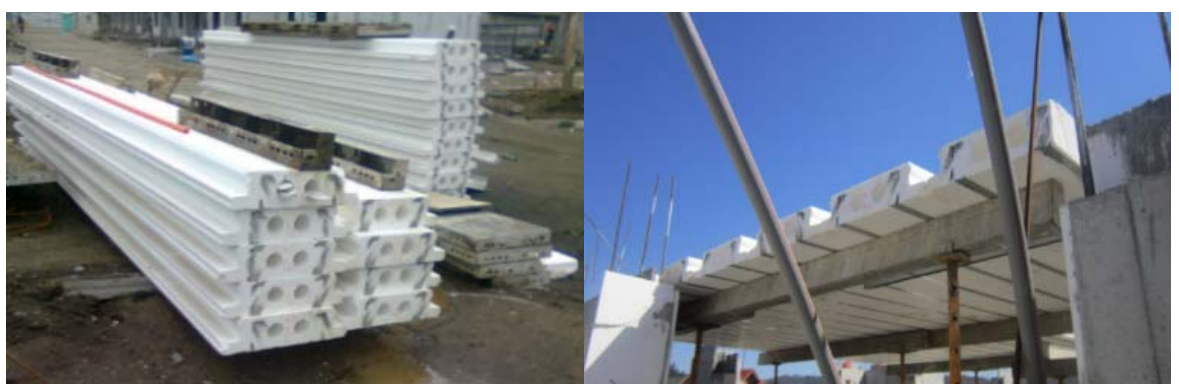

(a)

(b)

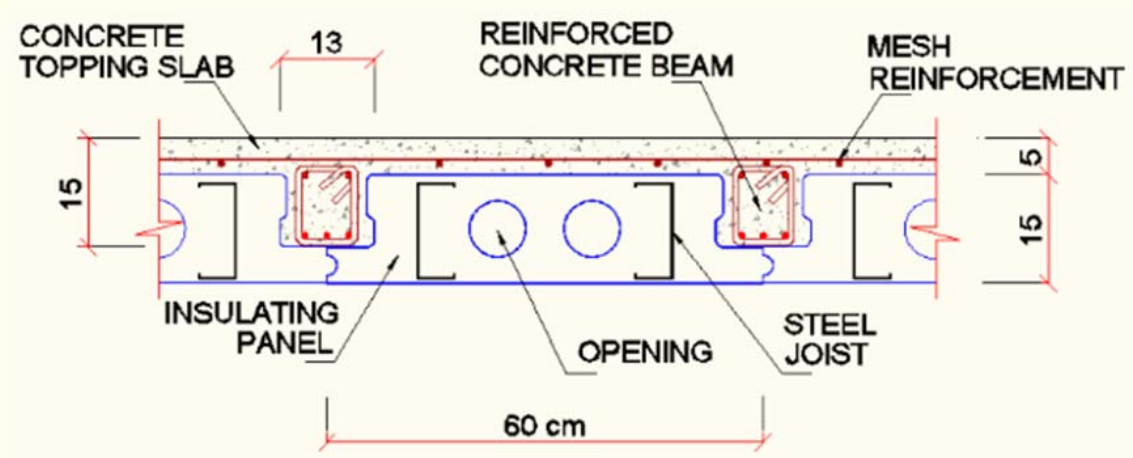

(c)

Table 1. Geometric characteristics of the evaluated slabs. Source: Self-Elaboration.

\begin{tabular}{cccc}
\multirow{2}{H}{$\begin{array}{c}\text { House } \\
\text { model }\end{array}$} & \multicolumn{2}{c}{ Support span $(\mathrm{m})$} & $\begin{array}{c}\text { Slab thickness } \\
(\mathrm{m})\end{array}$ \\
\cline { 2 - 3 } & Long dir. & Short dir. & 0.20 \\
\hline $\mathrm{M}_{1}$ & 4.98 & 3.33 & 0.20 \\
\hline $\mathrm{M}_{2}$ & 4.83 & 3.52 & 0.20 \\
\hline $\mathrm{M}_{3}$ & 5.03 & 3.10 & \\
\hline
\end{tabular}


Figure 2 shows one of the evaluated dwelling models with the respective accelerometer locations.

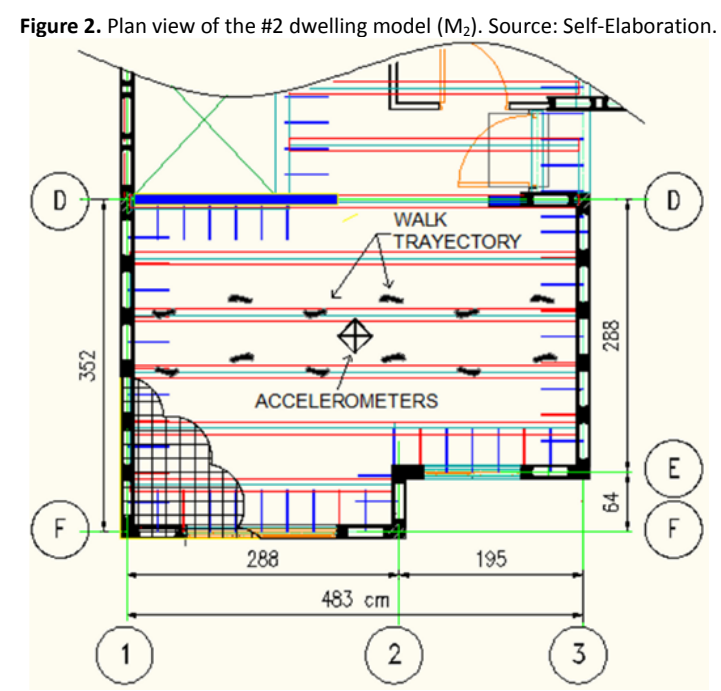

\subsection{Methodology for the on-site evaluation of the slabs' vibration performance.}

The short time available to perform the measurements, along with the need to minimize the impact on the construction in the termination phase, require an evaluation method that is fast, minimally invasive and technically efficient. The present work proposes an evaluation methodology of the vibration performance in three phases that satisfies the previously noted demands. For its elaboration, the recommendations proposed by the Steel Concrete Institute (Smith et al., 2009) and the ISO 10137 standard were taken into account.

\section{Phase 1: Determination of the dynamic properties of the floor systems}

To classify the type of vibration response of the slab, it is imperative to know the vertical vibration fundamental frequency. When a more complete dynamic characterization is needed, it is recommended to also estimate the damping ratio associated with the vibration frequency. There are diverse techniques to determine these properties, ranging from advanced procedures of experimental modal analysis to more approximate techniques. Within the latter category, the heel-drop method is highlighted (Blakeborough \& Williams, 2003) because in addition to its simplicity to be implemented on-site, it obtains results that are comparable to more advanced tests (Sedlacek et al., 2006).

The heel-drop test is conducted by having an individual who is standing in a strategic position on the slab raise their heels approximately $50 \mathrm{~mm}$ and then drop them, generating an impact with their own weight on the slab. In all of the heel-drop tests performed, the same individual, with a body mass of $86 \mathrm{~kg}$, was used to minimize the variability of the test. To obtain the fundamental vertical vibration frequency " $\mathrm{fn}$ " of the slab, the Fast Fourier Transform (FFT) was applied to the signal recorded during the heel-drop test. The vibration frequency generally corresponds to the frequency that generates the peak value of the FFT amplitude of the signal (Brandt, 2011). The half-power bandwidth method was applied to calculate the damping ratio " " associated with the vertical vibration fundamental frequency. This method operates in the frequency domain and is adequate to determine the modal damping ratios for each vibration's natural frequency when the system is excited by an impulsive load (Parnell, 2008).

\section{Phase 2: Determination of the step frequencies and body masses of the representative walkers.}

When walking or running, humans induce vertical, transverse and longitudinal dynamic loads, which are generated as a result of the displacement of their center of mass. The step frequency and the body mass of the walker are variables that characterize the dynamic loads generated (Racic, Pavic, \& Brownjohn, 2009). The step frequency "fp", defined as the number of steps per second in a walk, was measured in a group of 316 individuals in the city of Concepcion, Chile. The step frequencies obtained were fitted to a normal distribution, with representative values in the range of $1.4 \mathrm{~Hz}$ to $2.2 \mathrm{~Hz}$. The mean and standard deviation found were $1.80 \mathrm{~Hz}$ and $0.19 \mathrm{~Hz}$, respectively. 
In this way, five levels of step frequency were used to perform synchronized walks on the floor systems: $1.4 \mathrm{~Hz}, 1.6 \mathrm{~Hz}$, $1.8 \mathrm{~Hz}, 2.0 \mathrm{~Hz}$ and $2.2 \mathrm{~Hz}$. The separation between each level corresponds to approximately one standard deviation. According to the described methodology, at least two individuals with different body mass have to be selected to perform the synchronized walks. To define two extreme values of mass, the statistical records presented in the National Health Survey, 2009-2010 (Ministerio de Salud, 2010), were used. This report indicated that the average body mass of the population of Chile is $72.2 \mathrm{~kg}$, with a standard deviation of $14.2 \mathrm{~kg}$, corresponding to a normal distribution. Thus, subjects of $58 \mathrm{~kg}$ and $86 \mathrm{~kg}$ were selected to perform the walks, representing extreme weights that differ from the average values by one standard deviation.

\section{Phase 3: Criteria of dynamic serviceability against human-induced vibrations}

First, it is necessary to measure the vertical acceleration signal induced by one or more walks during a certain period of time. Because the acceptable vibration levels depend on the frequency of the movement, the acceleration recorded has to be weighted and filtered according to the parameters defined in the ISO 2631-1 standard (International Organization for Standardization, 1997). Subsequently, an adequate performance indicator is obtained. Within the indicators proposed by ISO 10137, the running root-mean-square (RMS) is significant, and it is defined by the expression shown in Equation 1:

$$
a_{w, r m s}\left(t_{0}\right)=\sqrt{\frac{1}{\tau} \int_{t_{0}-\tau}^{t_{0}}\left[a_{w}(t)\right]^{2} d t}
$$

Where $t$ : is the time (integration variable), $\tau$ : is the integration time for the running average, $t_{0}$ : is the observation time (instantaneous time), and $a_{w}(t)$ : is the instantaneous frequency-weighted acceleration.

The evaluation method with running RMS takes into account the spontaneous peaks in the transient vibration, depending on the integration time $\tau$ that is used. The $\tau$ value recommended by the ISO 10137 standard is one second.

Because in a vibration signal of several seconds duration there will be diverse values of running RMS acceleration, it is necessary to choose a single vibration performance indicator that represents the entire recorded signal. In the ISO 2631-1 standard, it is recommended to use the maximum transient vibration value (MTVV) as a performance indicator, as defined by Equation 2. Figure 3 shows an MTVV calculation example for one of the recorded accelerograms.

$$
M T V V=\max \left|a_{w, r m s}\left(t_{0}\right)\right|
$$

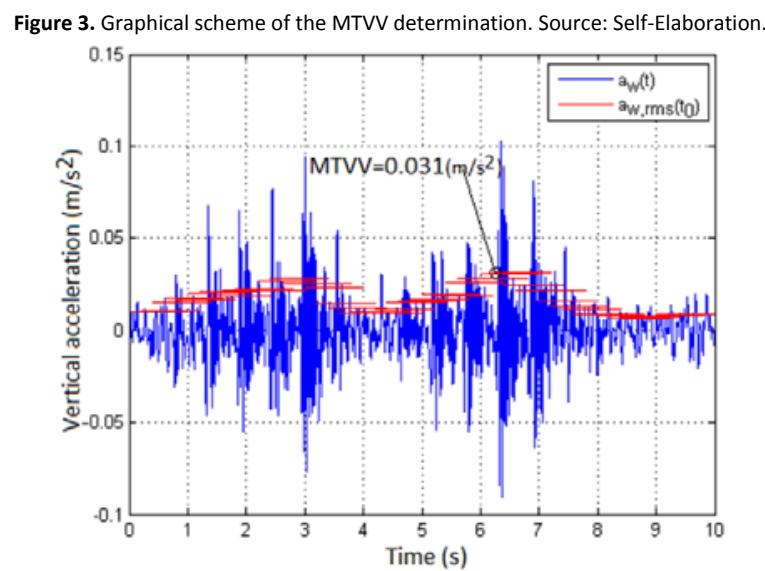

Once the MTVV indicator has been calculated for each accelerogram, the category of vibration performance to which each vibration belongs is verified. The ISO 10137 standard proposes to use a base curve of human perception to continuous and intermittent vibrations. The base curves depend on the vibration natural frequency of the structural system and on the orientation of the vibration relative to the human body axes. In this way, different thresholds of 
perception associated with different human occupation environments are defined through multiplication $\mathrm{R}$ factors of the base curve. Table 2 shows the typical values of R recommended by the ISO 10137 standard for continuous or intermittent vibrations. Figure 4 shows the shape of the perception base curve, with its respective $\mathrm{R}$ factors associated with the different physical environments and times.

Table 2. Multiplication R factors of the base curve defined in the ISO $\begin{gathered}\text { 10137 standard. Source: Self-Elaboration. } \\
\text { Environment or place }\end{gathered}$
\begin{tabular}{ccc} 
Time & Dactor \\
\hline Critical areas & Dayht & 1 \\
\cline { 2 - 3 } & Day & 2 to 4 \\
\hline Residential & Night & 1.4 \\
\hline Offices & Day & 2 to 4 \\
\hline Workshops & Night & 2 to 4 \\
\hline & Day & 8 \\
\hline
\end{tabular}

The ISO 10137 notes that if at a specific physical environment and time, the MTVV acceleration performance indicators do not exceed the level of the corresponding perception threshold curves, then, a low probability of adverse comments by the users is expected. In contrast, if the MTVV values are four times the level of the threshold perception curves, it is likely that the adverse comments will increase significantly, categorizing the performance of the floor system as insufficient.

Figure 4. Curves of the human perception threshold of vertical accelerations for different values of R, according to the ISO 10137 standard. Source: Self-Elaboration.

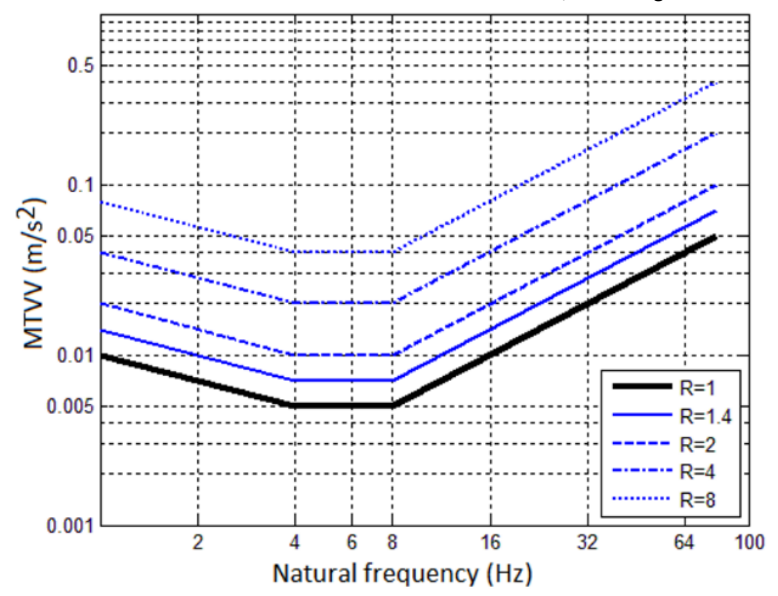

\section{Development of scenarios for the vibration performance evaluation.}

To evaluate the vibration performance of the DIFP-RC system under conditions of human walking, it was proposed to perform different combinations of the variables that most significantly influence the MTVV performance indicators. The coupled variables were the walker step frequency " $\mathrm{fp}$ ", body mass " $\mathrm{mc}$ " and the fundamental vertical vibration frequency "fn" of the slabs. Each one of these variables was manipulated at the following levels: $\mathrm{fp}[1.4 \mathrm{~Hz}, 1.6 \mathrm{~Hz}, 1.8$ $\mathrm{Hz}, 2.0 \mathrm{~Hz}$, and $2.2 \mathrm{~Hz}$ ], mc [58 kg and $86 \mathrm{~kg}$ ] and $\mathrm{fn}[24 \mathrm{~Hz}, 26 \mathrm{~Hz}$, and $28 \mathrm{~Hz}$. To synchronize the different step frequency levels of the individuals, a portable metronome was used. The levels assigned to the fundamental vibration frequency of the slabs were obtained from preliminary measurements in the three studied dwelling models (M1, M2 and $\mathrm{M} 3$ ).

In this way, a total of 30 combinations of variables were generated, in which a generic combination corresponds to an individual of a determined body mass, walking at a synchronized step frequency, in a specific dwelling model. Each one of these combinations of variables was repeated 12 times to establish an adequate sampling size. 
Dynamic properties of the floor systems.

The fundamental natural frequencies presented average values of $24.37 \mathrm{~Hz}, 25.94 \mathrm{~Hz}$ and $27.83 \mathrm{~Hz}$, for the dwelling models $M 1, M 2$ and $M 3$, respectively. The dwelling model $M 3$ presented the greatest dispersion in its natural frequency results, with a standard deviation of $1.76 \mathrm{~Hz}$. Regarding the measured damping ratios, the averages were $3.83 \%, 3.41 \%$ and $5.80 \%$ for the models $\mathrm{M} 1, \mathrm{M} 2$ and $\mathrm{M} 3$, respectively. The dwelling model $\mathrm{M} 3$ presented the greatest dispersion in its damping ratio results, with a standard deviation of $1.73 \%$.

The ISO 10137 standard classifies the types of vibration responses of the floor systems into two categories, depending on the fundamental vibration frequency $\mathrm{fn}$. If the floors have values of $\mathrm{fn}$ that are lower than the range between 8 and $10 \mathrm{~Hz}$, they are classified as low frequency, resonant floors. In contrast, if $\mathrm{fn}$ is greater than the indicated range, the floor is classified as high frequency and impulsive. From the values found, it can be deduced that the vibration response of the DIFP-RC systems is of impulsive-type and of high frequency. This is in agreement with the results shown in Figure 3 because one of the characteristics of these floors is that the vibration amplitude decreases between each step of the walks, without generating any resonance.

\section{MTVV performance indicators}

The greatest MTVV values where obtained when the individual weighing $86 \mathrm{~kg}$ walked at a frequency of $2.2 \mathrm{~Hz}$ in the dwelling model M2 $(0.094 \mathrm{~m} / \mathrm{s} 2)$. In contrast, the lowest MTVV values were obtained when the individual weighing 58 $\mathrm{kg}$ walked at a frequency of $1.4 \mathrm{~Hz}$ in the dwelling model M3 $(0.012 \mathrm{~m} / \mathrm{s} 2)$. For a single walk frequency and dwelling model, the individual weighing $86 \mathrm{~kg}$ always generated greater MTVV values than the individual weighing $58 \mathrm{~kg}$.

To determine the effects of the variables $\mathrm{fp}, \mathrm{fn}$ and $\mathrm{mc}$ on the mean values of the MTVV performance indicator, a balanced analysis of variance of the fixed effects was performed. The results of this analysis indicated that the individual effects of the factors $\mathrm{fp}, \mathrm{fn}$ and $\mathrm{mc}$ on the obtained mean values of the MTVV performance indicator are significant. This was verified when determining that the " $p$ values" obtained for each factor were always lower than the chosen significance level $\alpha(0.05)$. Figure 5 shows the interaction plot of the factors $\mathrm{fp}, \mathrm{fn}$ and $\mathrm{mc}$, on the mean values of the MTVV performance indicator.

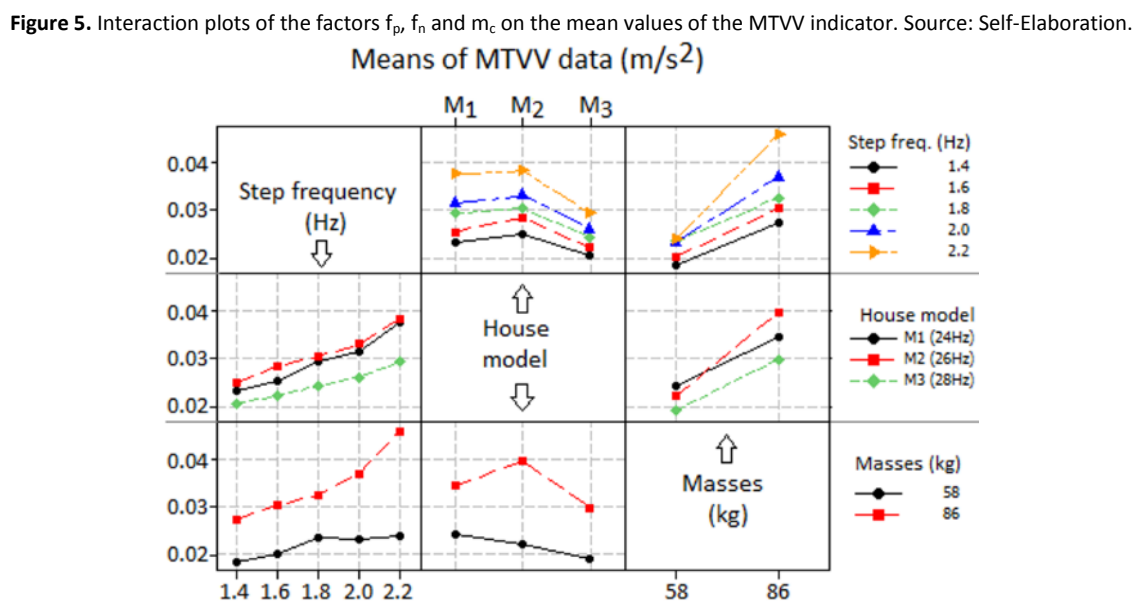

The plots of the left quadrants show that the MTVV mean values increased as the step frequency increased in the three dwelling models, with this effect being more pronounced for the walker with a body mass of $86 \mathrm{~kg}$. The plots of the right quadrants show that for all of the step frequencies and dwelling models, the MTVV mean values were greater with the walker with the higher body mass. Finally, the plots of the central quadrants show that when increasing the fundamental vibration frequency of the floors, decrements in the mean values of MTVV were not always obtained. In most cases, the dwelling model M2 presented the greatest mean values of the MTVV indicator. 


\section{Classification of the dynamic serviceability of the floor systems.}

Figure 6 shows the vibration performance of the M2 dwelling model, which obtained the worst results. For each dwelling model, 120 accelerograms of walks were recorded, for which their respective MTVV performance indicators were calculated. According to the criteria of the ISO 10137 for residential environments, when the curve with $R=8$ is exceeded for the day time, and the curve with $R=5.6$ is exceeded during the night time, insufficient vertical vibration performances of the floor systems are expected. Thus, adverse comments by the users should significantly increase in these situations. These values of R correspond to the quadrupling of the values proposed in Table 2 for residential environments.

The results obtained indicate that none of the walks performed in the three dwelling models will generate significant user discomfort due to vertical vibration during the day time. This was verified by observing that the vibration levels associated with the curves with $\mathrm{R}=8$ were never exceeded for that time. For the night time, the walks performed in the dwelling models $\mathrm{M} 1$ and $\mathrm{M} 3$ also did not generate significant discomfort because the curves with $\mathrm{R}=5.6$ were never exceeded. In dwelling M2, 99.2\% of the walks performed will not generate significant discomfort during the night time.

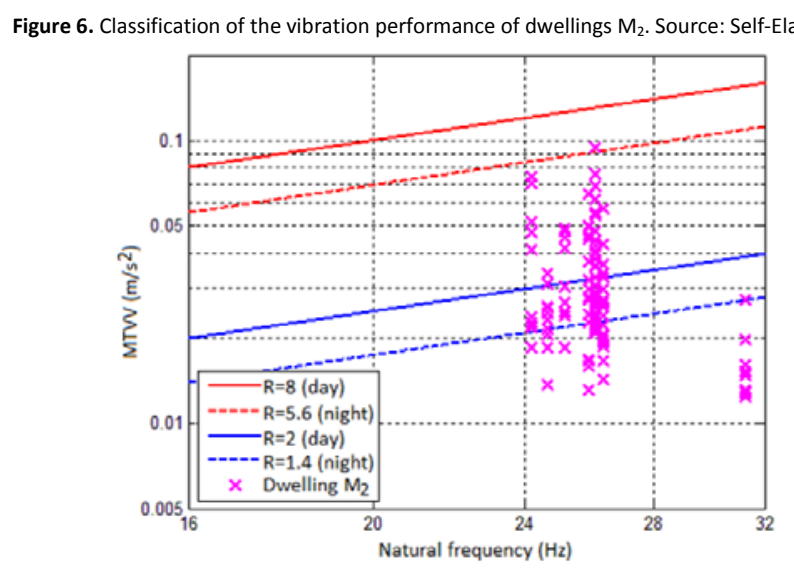

\section{Conclusions}

The obtained results show that the evaluated floor systems have an impulsive-type vibration response of high frequency, with vertical vibration natural frequencies that go from $23.44 \mathrm{~Hz}$ to $31.25 \mathrm{~Hz}$. The damping ratios had minimum and maximum values of $2.48 \%$ and $9.75 \%$, respectively. The MTVV vibration performance indicators, calculated for time periods of one second, showed values between $0.012 \mathrm{~m} / \mathrm{s} 2$ and $0.094 \mathrm{~m} / \mathrm{s} 2$. In general, the minimum values of MTVV were obtained when the individual of lower body mass walked at the lower step frequency in the dwelling models of greater vertical fundamental frequency. In contrast, the maximum values of MTVV were obtained when the individual of greater body mass walked at the highest step frequency in the dwelling models with a lower damping ratio. These two extreme situations can be used as preliminary evaluations of the vibration performance in construction contexts with less availability for performing on-site measurements.

The implementation of the serviceability criteria established by the ISO 10137 indicated that $100 \%$ and $97.22 \%$ of the evaluated dwellings did not generate significant discomfort to the users during the day time or night time, respectively. The above results demonstrate that the insulating floor panels used in contexts similar to the ones tested in this study are a convenient construction alternative to other lightweight floor systems because they present adequate vibration performance in response to human walking. 
Abeysinghe, C. M., Thambiratnam, D. P., \& Perera, N. J. (2013). Dynamic performance characteristics of an innovative Hybrid Composite Floor Plate System under human-induced loads. Composite Structures, 96, 590-600. http://doi.org/10.1016/j.compstruct.2012.09.015

Allen, D. E., \& Rainer, J. H. (1976). Vibration criteria for long-span floors. Canadian Journal of Civil Engineering, 3(2), 165-173. http://doi.org/10.1139/176-017

Bernstein, H., Gudgel, J., \& Laquidara-Carr, D. (2011). Smart Market Report - Prefabrication and modularization: increasing Productivity in the Construction industry. McGraw-Hill Construction.

Blakeborough, A., \& Williams, M. S. (2003). Measurement of floor vibrations using a heel drop test. Proceedings of the Institution of Civil Engineers Structures and Buildings, 156(4), 367-371.

Brandt, A. (2011). Noise and vibration analysis: signal analysis and experimental procedures. John Wiley and Sons.

Feldmann, M., Heinemeyer, C., \& Völling, B. (2007). Design guide for floor vibrations. Esch-sur-Alzette: ArcelorMittal, Commercial Sections.

Hanagan, L. M., Raebel, C. H., \& Trethewey, M. W. (2003). Dynamic Measurements of In-Place Steel Floors to Assess Vibration Performance. Journal of Performance of Constructed Facilities, 17(3), 126-135. http://doi.org/10.1061/(ASCE)0887-3828(2003)17:3(126)

Hu, L. J., Chui, Y. H., \& Onysko, D. M. (2001). Vibration serviceability of timber floors in residential construction. Progress in Structural Engineering and Materials, 3(3), 228-237. http://doi.org/10.1002/pse.69

International Organization for Standardization. ISO 2631-2:1989 Mechanical vibration and shock - Evaluation of human exposure to whole-body vibration - Part 2: Vibration in buildings $(1 \mathrm{~Hz}$ to $80 \mathrm{~Hz})$ (1989).

International Organization for Standardization. ISO 2631-1:1997 Mechanical Vibration and shock- Evaluation of human exposure to whole-body vibration- Part 1- General Requirements (1997).

International Organization for Standardization. ISO 2631-2:2003 Mechanical vibration and shock - evaluation of human exposure to whole-body vibration - part 2: vibration in buildings (1 Hz to $80 \mathrm{~Hz})(2003)$.

International Organization for Standardization. ISO 10137:2007 Bases for design of structures-serviceability of buildings and walkways against vibration (2007).

Lenzen, K. H. (1966). Vibration of steel joist-concrete slab floors. AISC Engineering Journal, 3(3), 133-136.

Middleton, C. J., \& Brownjohn, J. M. W. (2010). Response of high frequency floors: A literature review. Engineering Structures, 32(2), 337-352. http://doi.org/10.1016/j.engstruct.2009.11.003

Ministerio de Salud. (2010). Encuesta Nacional de Salud (ENS) Chile 2009--2010. Gobierno de Chile. Santiago.

Morán Proaño, M., \& Álvarez Rodríguez, O. (2012). Investigación de las vibraciones por tráfico en las construcciones patrimoniales de adobe. Revista de La Construcción, 11(2), 39-53. http://doi.org/10.4067/S0718-915X2012000200005

Murray, T., Allen, D., \& Ungar, E. (2003). Floor vibrations due to human activity (2nd ed.). American Institute of Steel Construction.

Onysko, D. (1988). Performance criteria for residential floors based on consumer responses. In Proceedings of International Conference on Timber Engineering (pp. 69-129).

Parnell, R. (2008). Vibration serviceability and dynamic modeling of cold-formed steel floor systems. University of Waterloo.

Parnell, R., Davis, B. W., \& Xu, L. (2010). Vibration Performance of Lightweight Cold-Formed Steel Floors. Journal of Structural Engineering, 136(6), 645-653. http://doi.org/10.1061/(ASCE)ST.1943-541X.0000168

Racic, V., Pavic, A., \& Brownjohn, J. M. W. (2009). Experimental identification and analytical modelling of human walking forces: Literature review. Journal of Sound and Vibration, 326(1-2), 1-49. http://doi.org/10.1016/j.jsv.2009.04.020

Reiher, H., \& Meister, F. (1931). The effect of vibration on people. Forschung Auf Dem Gebiete Des Ingenieurwesens, 2(11), 381-386.

Sedlacek, G., Heinemeyer, C., Butz, C., Volling, B., Waarts, P., Van Duin, F., ... Demarco, T. (2006). Generalisation of criteria for floor industrial, office, residental and public building and gymanstic halls. Office for Official Publications of the European Communities, 2006.

Setareh, M. (2010). Vibration Serviceability of a Building Floor Structure. II: Vibration Evaluation and Assessment. Journal of Performance of Constructed Facilities, 24(6), 508-518. http://doi.org/10.1061/(ASCE)CF.1943-5509.0000135

Setareh, M. (2012). Evaluation and assessment of vibrations owing to human activity. Proceedings of the Institution of Civil Engineers-Structures and Buildings, 165(5), 219-231.

Smith, A., Hicks, S., \& Devine, P. (2009). Design of floors for vibration: A new approach (2nd ed.). Ascot: The Steel Construction Institute.

Willford, M. and Young, P. (2006). A design guide for footfall induced vibration of structures. Trowbridge: The Concrete Centre.

Wiss, J. F., \& Parmelee, R. A. (1974). Human Perception of Transient Vibrations. Journal of the Structural Division, 100(ST4).

Xiong, H., Kang, J., \& Lu, X. (2011). Field Testing and Investigation of the Dynamic Performance and Comfort of Timber Floors. Journal of Asian Architecture and Building Engineering, 10(2), 407-412. http://doi.org/10.3130/jaabe.10.407 